\title{
Erratum to: Inductive responses of some organic metabolites for osmotic homeostasis in peanut (Arachis hypogaea L.) seedlings during salt stress
}

\author{
Asish Kumar Parida • Bhavanath Jha
}

Published online: 15 August 2014

(C) Franciszek Górski Institute of Plant Physiology, Polish Academy of Sciences, Kraków 2014

Erratum to: Acta Physiol Plant (2013) 35:2821-2832

DOI 10.1007/s11738-013-1315-9

In the original publication, the unit of Chl $a$, Chl $b$, Total $\mathrm{Chl}$ and Carotenoid has been published incorrectly in the Table 3. It should be ( $\mu \mathrm{g} \mathrm{g}^{-1}$ f.w.) instead of ( $\mathrm{mg} \mathrm{g}^{-1}$ f.w.).

The online version of the original article can be found under doi: 10.1007/s11738-013-1315-9.

A. K. Parida $(\bowtie) \cdot$ B. Jha Discipline of Marine Biotechnology and Ecology, CSIR-Central Salt and Marine Chemicals Research Institute (CSIR-CSMCRI), Gijubhai Badheka Marg, Bhavnagar 364002, Gujarat, India e-mail: asishparida@csmcri.org 